\title{
O Que Falta Discutir sobre a Saúde Pública Brasileira
}

\author{
What is Missing over the Discussion about the Brazilian \\ Public Health
}

\begin{abstract}
Muito tem se falado sobre a situação do sistema de saúde no Brasil, tanto em razão das manifestações que ocorreram no país durante o final do primeiro semestre deste ano, como também em função da lei do Ato Médico e da criação do Programa Mais Médicos. Mas, além das alternativas apresentadas pelo governo, o que mais poderia ser proposto para atender às reivindicações por melhorias na rede pública de saúde? Miguel Srougi, urologista e professor titular da Faculdade de Medicina da Universidade de São Paulo, em entrevista para a Revista Cultura e Extensão USP, procura colaborar com a resposta a essa pergunta, oferecendo um novo panaroma sobre questões já tão debatidas atualmente em nosso país.

A partir de dados relevantes e de um ponto de vista crítico sobre o que interfere de forma direta no dia a dia da população, ele traz à tona preocupações que devem suscitar novas dúvidas a respeito dos prós e contras do atendimento de saúde oferecido aos brasileiros em regiões mais afastadas e nos grandes centros urbanos.
\end{abstract}

Revista Cultura e Extensão USP - O número de médicos formados por instituições públicas e particulares tem sido suficiente para suprir a demanda por esses profissionais no país? Miguel Srougi - Na verdade, o mundo inteiro tem falta de médicos, essa é uma constatação que agora está se tornando clara. Calculou-se que, nos Estados Unidos, faltam aproximadamente 15.200 médicos na atenção à saúde básica. No estado do Texas há menos médicos por habitante que no Brasil. Na Inglaterra, os hospitais de emergência na região de Yorkshire não contam com médicos à noite, sendo que têm sido convocados militares médicos do Exército para cobrirem o serviço de emergência durante esse período. $\mathrm{O}$ que eu estou querendo dizer é que o mundo inteiro está precisando criar mecanismos para oferecer mais médicos para as populações.

Uma das razões para o aumento da demanda no setor está relacionada ao envelhecimento da população. Nossa pirâmide etária está quase de cabeça para baixo e os idosos têm alta demanda por assistência médica. Isso significa que está crescendo o número de pessoas que precisam ser tratadas, apoiadas, orientadas, e os médicos, embora venham aumentando em número, não estão sendo suficientes. Nos últimos anos, o número de

\section{Marina Salles}

Universidade de São Paulo. Escola de Comunicações e Artes, São Paulo, Brasil

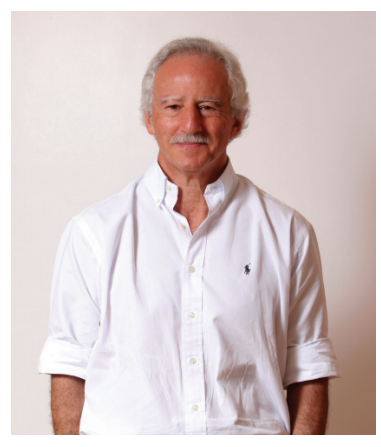

Miguel Srougi é urologista e professor titular da Faculdade de Medicina da Universidade de São Paulo 
vagas nas escolas médicas brasileiras aumentou em quase 70\%, apesar disso, a quantidade de médicos por habitante está aquém do ideal. O governo precisa adotar medidas para compensar um pouco esse desequilíbrio, o que é algo difícil quando ações são pautadas por interesses pessoais, de grupos ou com função eleitoreira.

RCE - A criação de novas Escolas de Medicina seria uma alternativa viável para suprir a falta de médicos no Brasil? Além disso, de que maneira uma melhor distribuição dessas instituições de ensino poderia contribuir para a melhoria do quadro de inoperância do sistema de saúde nas áreas mais afastadas?

MS - Aumentar a quantidade de escolas médicas é uma necessidade, mas é também algo muito caro, sendo que você precisa ter não só uma tremenda estrutura física e de equipamentos, como também, dispor de professores, o que não é muito simples. Os professores existem. Todos os formados na área Médica são professores em potencial, mas se você quiser criar escolas médicas boas é necessário que eles estejam preparados para isso. É importante que os professores tenham vocação genuína e saibam como prover educação médica e não apenas transmitir conhecimentos.

A criação de escolas em locais mais distantes é talvez menos eficaz do que possa parecer à primeira vista, já que os médicos não se fixam nos lugares em que fizeram o seu curso de Graduação, mas sim em lugares atraentes para o exercício profissional. Nesse sentido, espalhar as escolas médicas tem um valor social: faz com que as pessoas que vivem nas zonas mais afastadas dos grandes centros possam se decidir pela carreira, sem a necessidade de se deslocar para longe, o que é caro e às vezes impossível para quem vem de áreas remotas. Agora, em termos de fixar os indivíduos no local, tal estratégia não funciona, o pessoal se forma e vai para onde há oportunidades de crescer profissionalmente.

De qualquer maneira, o número de médicos precisa crescer e uma proposta que me atrai seria, ao invés de criar mais escolas médicas, aumentar o número de alunos por meio de algum financiamento governamental que permitisse o aproveitamento da infraestrutura que já existe. Aumentando em $20 \%$ ou $30 \%$ a quantidade de alunos em instituições existentes seria possível usar uma estrutura montada e rapidamente começar a incorporar estudantes à graduação. Essa proposta é perfeitamente assimilável para a maioria das escolas médicas. Se fôssemos criar novas escolas, talvez em 2020 ainda não se teria avançado nessa questão.

RCE - E o Programa Mais Médicos seria uma solução nesse sentido?

MS - O governo brasileiro adotou uma medida simples de grande apelo popular com a criação do Programa Mais Médicos, mas essa solução é falaciosa porque os grandes gargalos da saúde pública brasileira são a ausência de infraestrutura e de gerenciamento eficiente; também há falta de recursos financeiros, de interesse sincero e de sensibilidade dos nossos governantes. Com isso, não se criou um sistema de saúde que ofereça atendimento de qualidade, principalmente, na assistência primária. Colocar médicos estrangeiros nas pequenas cidades gera, então, um tremendo apelo, de repente uma cidade que não tinha nenhum profisional vai contar com dois ou três médicos; mas eles não vão conseguir proporcionar saúde minimamente decente, o que eles vão fazer qualquer outro profissional paramédico teria condições de fazer também.

Durante semanas o governo e a imprensa oficialista documentaram insistentemente 
a chegada desses médicos, quiseram criar a impressão de que estava chegando uma legião de estrangeiros no Brasil. Entrevistavam sempre as mesmas pessoas, contando as histórias de uns e de outros, enaltecendo suas características humanísticas, que nem sabemos se são reais, procurando seduzir o povo brasileiro, o que acho que conseguiram temporariamente, até que a empulhação apareça de forma clara.

Neste ano o Brasil vai formar 13 mil médicos; se esses médicos tivessem apoio financeiro, material e a colaboração de outros agentes da saúde, tenho a impressão de que uma parcela deles aceitaria de bom grado ir trabalhar na área de saúde básica em regiões remotas. Ao invés de financiar Cuba, estaríamos pagando para os brasileiros, oferecendo oportunidade e vida digna para os nossos cidadãos.

RCE - Em sua opinião, o que tem motivado esses médicos estrangeiros a virem para o Brasil? MS - Os médicos que estão migrando para cá vieram porque estão mal nos países deles. Só por isso; não porque o Brasil tem um projeto maravilhoso. $\mathrm{O}$ assunto tem sido focado nos valores humanos desses profissionais, que afirmam terem vindo para cá a fim de ajudar os brasileiros, mas que vão ganhar 80 vezes mais do que eles ganham em seus países de origem e vão viver em um país lindo, onde, apesar de existir pobreza, prevalece a liberdade. Então, fica fácil entender o porquê do trabalho humanitário.

Você acha que os médicos cubanos vão melhorar alguma indecência que nós temos na saúde? Até nas grandes cidades estamos cheios de problemas; sabe quanto tempo um doente demora para ser internado na Divisão de Urologia do Hospital das Clínicas de São Paulo? Em média, são seis meses; se ele tiver câncer, serão três ou quatro meses; se ele for portador de um rim bloqueado e sem funcionar, poderão ser até oito meses. Atualmente, existem 1.450 pacientes na fila de espera para internação nessa Divisão e a Urologia representa apenas 1/35 do Hospital das Clínicas.

RCE - E o que motivaria os brasileiros a deslocar-se para atender a demanda por profissionais nas áreas periféricas?

MS - Nenhum médico fez juramento de pobreza. Ele quer trabalhar onde ele possa viver bem, onde ele possa se atualizar, onde ele tenha colegas com quem conversar, onde ele tenha acesso aos congressos, às bibliotecas, às revistas, aos eventos científicos que o façam crescer. É óbvio que dinheiro também tem valor, mas a prova de que a questão não é material, como o governo tenta insinuar (os médicos brasileiros seriam gananciosos), é que nas cidades pequenas os prefeitos pagam quantias de dinheiro absurdas para os médicos irem para lá, mas a maioria se nega a prestar esse serviço.

Tem lugar que oferece de 15 mil a 20 mil reais de salário para que os médicos aqui do Brasil trabalhem no interior, só que logo surgem problemas. Primeiro que, após poucos meses, os salários frequentemente deixam de ser pagos e os médicos acabam desistindo. Vão embora e cidades com prefeitos desonestos têm que oferecer salários cada vez mais altos, não pela ganância médica, mas pela perspectiva de calote aos médicos. Segundo que, algumas vezes, nas cidades pequenas, os médicos fazem mais sucesso que os prefeitos e isso cria uma dinâmica perversa. $\mathrm{O}$ médico atende à população carente e o prefeito, enciumado, para de pagar o profissional. Esse é outro motivo que obriga prefeitos a oferecerem salários maiores, que não serão honrados. 
O Mais Médicos caiu do céu para os prefeitos mal intencionados, pois agora eles podem demitir médicos contratados, substituindo-os por profissionais oferecidos pelo Governo Federal. Os médicos passam a ganhar R \$10 mil por mês e a prefeitura fica livre desse ônus.

RCE - Além da bolsa auxilio e de uma ajuda de custo para moradia, algum dos nossos direitos trabalhistas está reservado aos médicos que participam do programa? Essa medida não é discutível?

MS - O dinheiro que vai ser pago aos médicos do programa é injusto e ilegal. Para uma sociedade pobre como a nossa, essa quantia parece, à primeira vista, um salário imenso, mas essa pessoa não tem $13^{\circ}$, não tem férias, direito trabalhista, fundo de garantia, não tem nada, tampouco progressão na carreira. Totalmente irregular e inconstitucional. Demonizando os médicos brasileiros, o governo conseguiu implementar essa medida e, por isso, ninguém tem coragem de reclamar. E, assim, essa situação é omitida, enquanto o governo se utiliza de eufemismos e repete o óbvio, que é necessário, sim, atender aos mais pobres: "precisamos pensar nesses outros seres humanos".

RCE - Como o senhor encara a questão da humanização da Medicina? Quais melhorias poderiam ser adotadas nesse sentido? Aumentar o contato dos estudantes com os pacientes e oferecer mais disciplinas relacionadas ao tema na grade do curso são alternativas?

MS - Os médicos se preocupam com isso mais do que as pessoas imaginam. O nosso curso de Urologia é composto de nove períodos, sendo que dois deles são só sobre humanização. A gente não fala em rim, bexiga, próstata. O que acontece é que o processo de humanização é um processo complexo. Você não ensina humanização em uma sala de aula, você ensina pelo exemplo. Por isso é preciso ter professores comprometidos com essa ação. As Faculdades de Medicina discutem isso a todo momento, mas falta implementar uma melhor estratégia prática a respeito. É preciso identificar os verdadeiros modelos e colocá-los para ensinar. Os médicos ligados à Academia gostam de dar aulas para os alunos de graduação, muitas vezes com o objetivo de engrossar seus currículos, mas, em muitos casos, estão despreparados para transmitir ensinamentos humanísticos. As escolas médicas deixam de reconhecer essa situação.

$\mathrm{RCE}$ - Em relação à proposta de serviço obrigatório a ser realizado no SUS por estudantes de Medicina que ingressarem na faculdade a partir de 2015, qual a sua opinião?

MS - Essa é outra medida equivocada. Você não pode ferir o direito à liberdade das pessoas; você não pode obrigar alguém a trabalhar onde não quer. É preciso atrair e não obrigar, pois essas são coisas bem diferentes. Depois das manifestações de junho, o governo propôs um aumento do curso de graduação médica de seis para oito anos, incorporando dois anos de estágio obrigatório no SUS. Pretendia aumentar a mão de obra barata para a assistência às populações carentes, sem compromisso sério com os estudantes de Medicina - ao lançá-los à prática clínica totalmente despreparados para tal - e, pior do que isso, colocando em risco a saúde dos desassistidos.

Outro assunto importante que deveria receber atenção, inclusive antes de serem feitas novas propostas de mudança no curso de Medicina, diz respeito à criação de residências médicas. O Brasil forma 13 mil médicos e tem agora 7 mil vagas no país, o que 
significa que entre 5.000 e 6.000 estudantes ficam sem treinamento todos os anos. $\mathrm{O}$ governo nunca deu importância para isso e agora fala em criar residências sem compreender a real dimensão do que essa questão representa. Abrir novas vagas não é simples, você precisa ter hospitais bons e, acima de tudo, bons professores e programas capacitados. Ademais, a proposta governamental promete um número de novas vagas para residência, que até para qualquer iniciante no tema, é notoriamente irreal e inexequível.

Propuseram, também, que os hospitais filantrópicos passasem a atender mais doentes carentes, como forma de pagar suas dívidas tributárias. Nada mais surrealista, já que essas instiutições tornaram-se inadimplentes justamente por atender pacientes do SUS e não serem ressarcidas honestamente pelo Governo Federal. Para se ter uma ideia do descalabro, em hospitais públicos que dão atendimento a pacientes do SUS, uma mulher submetida a uma cesariana custa para o hospital $\mathrm{R} \$ 2.038,00$, sendo que o SUS paga ao hospital cerca de $\mathrm{R} \$ 550,00$ pelo procedimento, que inclui $\mathrm{R} \$ 150$,00 para a equipe médica e R\$290,00 para o hospital.

RCE - De que maneira a Faculdade de Medicina da USP contribui para atenuar essa falta de vagas em residência médica?

MS - A FM-USP cumpre seu papel social nesse processo. Formam-se, a cada ano, em nossa institutição, 180 alunos e, segundo o Ministério da Educação (MEC), as escolas médicas têm que oferecer $70 \%$ de vagas de residência em função do seu número de alunos. Considerando essa porporção, a FM-USP deveria disponibilizar em torno de 150 vagas anuais para novos residentes, mas atualmente oferecemos 540. Estamos ajudando a formar médicos graduados em todo o país, suprindo a defiência de outras escolas e retribuindo à sociedade, de forma comprometida, o apoio que dela recebemos.

RCE - Qual a verba destinada à saúde pública no Brasil?

MS - O Governo Federal destinou ao Ministério da Saúde em 2012 mais ou menos R\$ 90 bilhões para gerenciar todos os níveis de atenção à saúde. Mas, no fim desse mesmo ano, esse Ministério deixou de gastar R 9 bi por inoperância e incompetência dos seus gestores. Com $\mathrm{R} \$ 9$ bilhões poderiam ter sido construídas e equipadas 18 mil Unidades Básicas de Saúde, essas clínicas dispersas pela periferia e locais mais pobres, onde os pacientes são atendidos de forma resolutiva, reduzindo a demanda incontrolável nos hospitais públicos. Outro cálculo demonstra que, com R $\$ 9$ bilhões, poderiam ter sido construídos e equipados cerca de 90 hospitais, com 200 leitos cada, para atender às pessoas carentes.

O Brasil perde, com a corrupção nos órgãos públicos, cerca de 70 bilhões de reais por ano, segundo a Fundação das Indústrias do Estado de São Paulo (FIESP), ou R \$ 200 bilhões, de acordo com a ONU. Mais que o dobro dos recursos que o Ministério da Saúde dispõe para dar atendimento médico a todo o povo brasileiro, de assistência primária a campanhas de vacinação e prevenção de doenças, fornecimento de medicamentos, finaciamento à rede de hospitais e serviços de emergência. Se eles conseguissem preservar um terço desse dinheiro manchado, estariam disponíveis cerca de $\mathrm{R} \$ 6$ o bilhões, que poderiam ser investidos na saúde, contribuindo para atenuar a situação que enfrentamos hoje.

O pouco caso com a saúde reflete-se em outra estatística vergonhosa. A Argentina destina mais ou menos $20 \%$ do seu PIB para a saúde, a Colômbia $18 \%$ e o Brasil 8,7\%, menos 
do que a média africana, que é da ordem de 10,5\%. Em resumo, e apesar do discurso oficial mentiroso, destinam-se poucos recursos para a área da saúde brasileira e essa improcedência é agravada pelos desvios criminosos e as perdas impostas pela inoperância governamental.

\section{RCE - Pensando nessas comparações, que exemplos o Brasil poderia seguir?}

MS - No Canadá também faltam médicos, mas lá eles optaram por medidas consistentes para enfrentar o problema. Contrataram profissionais de outros países e fizeram um ranking de universidades. Assim, se o médico vem de uma universidade boa, ele não precisa fazer o exame para ir trabalhar lá e os que vêm de faculdades mal rankeadas fazem o exame. Uma vez aprovados, os médicos ocupam postos na saúde pública em cidades pequenas, recebem um salário condigno, auxiliam as esposas a terem empregos estáveis, seus filhos têm acesso à escola gratuita e de qualidade e o médico também pode manter relação com uma rede médica que lhe proporciona acesso a bibliotecas digitais, eventos e outros contatos da área. Esse sim é um projeto completo para importar médicos.

No Brasil há muito que se fazer e uma solução seria fixar médicos oferecendo boas condições de vida para eles; outra ação relevante seria oferecer uma ajuda real para que as pessoas carentes pudessem sair do estado de pobreza. O Bolsa Família foi uma medida boa, mas ela está ruindo por um motivo muito simples: esse dinheiro é distribuído para as pessoas, elas ascendem socialmente, começam a comprar comida, roupa, objetos pessoais - isso foi uma coisa grandiosa - só que o governo esqueceu de exigir que os filhos dessas famílias crescessem do ponto de vista educacional. Claro, existem as regras, o Bolsa Família exige que as crianças frequentem a escola, que tenham carteira de vacinação, tudo direito, mas o governo não cobra isso e vai cobrar menos agora, porque é época eleitoral.

As famílias ascenderam, os filhos não estão estudando, não têm saúde e o que vai acontecer quando essas crianças forem adultas? O mais provável é que elas migrem de volta para a pobreza, porque, nas sociedades contemporâneas, sem educação e saúde ninguém sai da indigência.

Além disso, seria possível privilegiar um programa que já existe, o Programa de Saúde da Família (PSF), que foi idealizado pelo professor Adib Jatene e tem como base a criação de equipes multiespecialistas de saúde em comunidades carentes. Essas equipes atendem um certo número de habitantes e dão apoio a eles, sendo formadas por médicos, enfermeiros, dentistas, psicólogos e assistentes sociais. Estruturado de maneira simples, o programa representa um modelo excelente para suprir a necessidade de atendimento à população de baixa renda. O problema é que menos da metade da populacão brasileira tem direito ao PSF e, em muitos casos, as equipes se dissolveram por falta de pagamento.

Nós médicos também erramos com a insistência na aprovação da lei do Ato Médico. É importante permitir que profissionais paramédicos atuem nas pequenas cidades nos casos de assistência primária. Criar um posto de saúde e colocar para trabalhar nesse local enfermeiros, psicólogos e farmacêuticos é uma saída para começar a mudar o quadro de assistência à população que reside em locais remotos, onde médicos não querem clinicar.

RCE - A busca pela aprovação da lei do Ato Médico não é justificável no contexto da saúde pública brasileira?

MS - O Ato Médico tem sentido quando o assunto diz respeito ao atendimento de 
moléstias complexas ou quando procedimentos mais sofisticados são necessários para uma ação médica eficiente. Contudo, sua proposta carrega certo traço corporativista, por não admitir qualquer ação em saúde que não seja realizada por médicos.

Em países pobres e com carência desses profissionais não se pode impor o Ato Médico. Nesses locais, outros profissionais da área da saúde, com certo preparo e experiência prática, podem suprir com relativa eficiência a ausência de médicos no trato de problemas básicos de saúde. Até nos Estados Unidos, rigoroso com a prática da Medicina, enfermeiras e paramédicos em saúde podem prescrever medicação, examinar doentes, ajudar em cirurgias e isso aumenta o número de profissionais disponíveis para o atendimento.

RCE - Por fim, é possível afirmar que a discrepância entre o número de médicos especialistas e generalistas prejudica o atendimento à saúde básica, principalmente na rede pública de saúde? MS - A fragmentação é uma tendência não só da Medicina, mas também de outras áreas do saber. $\mathrm{O}$ conhecimento médico está se tornando muito vasto, muito específico, então não dá para um profissional dominar todos os avanços da Ciência Médica. O sujeito, quando faz Urologia, começa a estudar um campo específico e se torna um grande conhecedor do assunto para poder exercer a função dele com muito mais facilidade, eficiência e êxito. Uma das frases, cujo autor ignoro, mas que reflete com graça o momento médico atual diz que "o generalista entende nada de quase tudo e o especialista entende tudo de quase nada”. Mas essa é uma tendência própria do ser humano, querer conhecer profundamente a área em que atua.

Existe um problema também de recompensação financeira: os especialistas ganham muito mais do que os generalistas. Essa situação cria insatisfações e, às vezes, desalento, pois, mesmo os médicos impregnados de sentimentos humanísticos e que se colocam ao lado dos mais humildes, também têm aspirações de propiciar uma vida digna para si mesmos e para as suas famílias.

Como um bom governo agiria para corrigir essa distorção? Criando facilidades e dando incentivos para se trabalhar na área básica. Como se cria isso? Como o Canadá fez, pagando um salário melhor, oferecendo moradia para o médico viver descentemente, garantindo uma boa estrutura de direitos para ele e chances de o médico continuar se aperfeiçoando. Assim você atrai gente para a saúde pública. Criticar os médicos é fácil, mas essa pessoa iria para um rincão trabalhar nas condições oferecidas a essa categoria profissional? Ninguém vai, ninguém quer viver assim.

MARINA SALLES graduanda do curso de Jornalismo da Escola de Comunicações e Artes da Universidade de São Paulo e bolsista da Revista Cultura e Extensão USP - e-mail: marina.salles.jor@gmail.com

+ CULTURA E EXTENSÃO NA INTERNET

Saiba mais sobre dois projetos de extensão desenvolvidos pela USP em: www.prceu.usp.br/revista

Envelhecer Sorrindo: A professora Maria Luiza Frigerio, da Faculdade de Odontologia da USP, fala sobre o projeto que trata de pacientes idosos.

Poli Cidadã: Antonio Luís Mariani fala sobre a iniciativa que procura oferecer novas soluções para demandas sociais, de modo a contribuir com o aprendizado dos alunos da Escola Politécnica da USP. 